\title{
DESKRIPSI PROFIL WARUNG KOPI KIWARI DAN KARAKTERISTIK KONSUMENNYA YANG MENGONSUMSI KOPI ARABIKA MANGLAYANG KARLINA
}

\section{PROFILE OF KIWARI COFFEE SHOP AND THE CONSUMERS CHARACTERISTIC THAT CONSUME ARABICA COFFEE MANGLAYANG KARLINA}

\author{
MUHAMMAD FADLI*, KUSWARINI KUSNO \\ Fakultas Pertanian, Universitas Padjadjaran \\ *fadli sukses091096@yahoo.com, kuswarini.kusno@unpad.ac.id
}

\begin{abstract}
ABSTRAK
Kiwari Farmers adalah kelompok tani kopi yang memproduksi kopi arabika bernama Manglayang Karlina dan dipasarkan di warung kopi Kiwari. Meningkatnya jumlah kedai kopi di daerah Bandung menimbulkan persaingan yang semakin ketat dalam industri kopi. Salah satu dampaknya adalah omzet warung kopi Kiwari berfluktuasi selama tahun 2018 Hal ini juga disebabkan jumlah konsumennya menurun. Karena itu, perlu diketahui bagaimana karakteristik konsumennya, agar warung kopi Kiwari dapat menjaga eksistensinya. Penelitian ini bertujuan untuk mendeskripsikan profil Kiwari Farmers dan karakteristik konsumen kopi Manglayang Karlina di Warung Kopi Kiwari. Untuk mencapai tujuan pertama, data dan informasi dikumpulkan dari informan. Sedangkan untuk tujuan kedua, dilakukan survey terhadap sampel responden berukuran 50 yang dipilih secara sengaja (purposive sampling). Data terdiri dari data primer yang dikumpulkan dengan cara wawancara dan menggunakan kuesioner, serta data sekunder yang diperoleh dari studi literatur dan instansi terkait. Data dianalisis secara deskriptif kualitatif dan dengan menggunakan tabel frekuensi. Kiwari Farmers berperan sebagai produsen dan pedagang. Sebagai produsen, Kiwari Farmers memproduksi kopi arabika Manglayang Karlina dan kopi Luwak Manglayang. Budidaya tanaman kopi dilakukan di kebun milik pribadi dan diolah secara mandiri dari hulu hingga hilir. Sebagai pedagang, warung Kopi Kiwari menjual bermacam-macam merk kopi yang masing-masing diperoleh dari petani di daerah asal kopi tersebut. Mayoritas responden konsumen adalah laki-laki, berusia rata-rata 20 tahun, belum bekerja, memiliki uang saku per bulan rata-rata $\mathrm{Rp} 1.568 .000$, sedang menempuh pendidikan sarjana, dan berdomisili di dalam Bandung. Disarankan Kiwari meneliti kepuasan konsumen sebagai acuan untuk menentukan sasaran-sasaran di tahun-tahun mendatang.
\end{abstract}

Kata Kunci: Kopi, kedai kopi, karakteristik konsumen, kelompok tani

\begin{abstract}
Kiwari Farmers is a coffee farmer group that produces arabica coffee called Manglayang Karlina and is marketed in the Kiwari coffee shop. The increasing number of coffee shops in the Bandung area has led to increasingly fierce competition in the coffee industry. One impact is the turnover of the Kiwari coffee shop fluctuating during 2018 This is also due to the number of consumers declining. Therefore, it is necessary to know how the characteristics of consumers are, so that the Kiwari coffee shop can maintain its existence. This study aims to describe the profile of Kiwari Farmers and the characteristics of Manglayang Karlina coffee consumers at Warung Kopi Kiwari. To achieve the first objective, data and information are collected from informants. Whereas for the second purpose, a survey of 50 sample respondents was chosen purposively (purposive sampling). The data consists of primary data collected by interview and using a questionnaire, and secondary data obtained from literature studies and related agencies. Data were analyzed descriptively qualitative and by using frequency tables. Kiwari Farmers acts as a producer and trader. As a producer, Kiwari Farmers produces Manglayang Karlina coffee and Luwak Manglayang coffee. Coffee cultivation is carried out in privately owned farms and is processed independently from upstream to downstream. As a trader, the Kiwari Coffee shop sells a variety of coffee brands, each obtained from farmers in the area of origin of the coffee. The majority of respondents were male, average age of 20 years, not working, had an average monthly allowance of IDR 1,568,000, were pursuing undergraduate education, and were
\end{abstract}


domiciled in Bandung. It is recommended that Kiwari coffe shop conduct research on consumer satisfaction as a reference for setting goals in the coming years.

Keywords: Coffee, coffee shop, consumer characteristics, farmer group

\section{PENDAHULUAN}

Dalam perekonomian Indonesia, komoditas kopi berperan sebagai sumber devisa negara, penghasil bahan baku industri, dan penyedia lapangan kerja melalui kegiatan pengolahan, pemasaran, dan perdagangan (Rau, 2014).

Menurut FAO (2015), Indonesia merupakan salah satu produsen kopi terbaik dengan ciri khas daerah yang berbeda-beda seperti Java Preanger, Aceh Gayo, Bali Kintamani, Toraja, Papua Wamena dan lainnya. Hasil produksi kopi Indonesia saat ini menempati peringkat ke 4 terbesar setelah Brazil, Colombia, dan Vietnam (ICO, 2018). Sekitar 70\% dari total produksi kopi di Indonesia untuk diekpor (lihat Tabel 1).

Tabel 1. Produksi, volume, dan nilai ekspor kopi Indonesia Tahun 2013-2017

\begin{tabular}{l|c|c|c}
\hline \multirow{2}{*}{ Tahun } & \multirow{2}{*}{$\begin{array}{l}\text { Produksi } \\
\text { (ton) }\end{array}$} & Volume & $\begin{array}{l}\text { Nilai } \\
\text { (x1000USD) }\end{array}$ \\
\hline 2013 & 675.881 & 534.023 & 1.174 .029 \\
\hline 2014 & 647.857 & 384.816 & 1.039 .341 \\
\hline 2015 & 639.412 & 502.021 & 1.197 .735 \\
\hline 2016 & 639.305 & 414.651 & 1.008 .549 \\
\hline 2017 & 637.539 & 467.799 & 1.187 .157 \\
\hline
\end{tabular}

Sumber: Kementerian Pertanian (2018)
Popularitas dan daya tarik dunia terhadap kopi terutama dikarenakan rasanya yang unik serta didukung oleh faktor sejarah, tradisi, sosial dan kepentingan ekonomi (Ayelign et al, 2013). Tanaman kopi biasanya diolah menjadi minuman yang memiliki cita rasa khas yang tidak dimiliki oleh bahan minuman lainnya. Selain itu kopi merupakan sumber alami kafein (Nawrot et al, 2003), yaitu zat yang dapat menyebabkan peningkatan kewaspadaan dan mengurangi kelelahan (Smith, 2002).

\section{KONSUMSI KOPI DI INDONESIA} (X $1000 \mathrm{TON})$

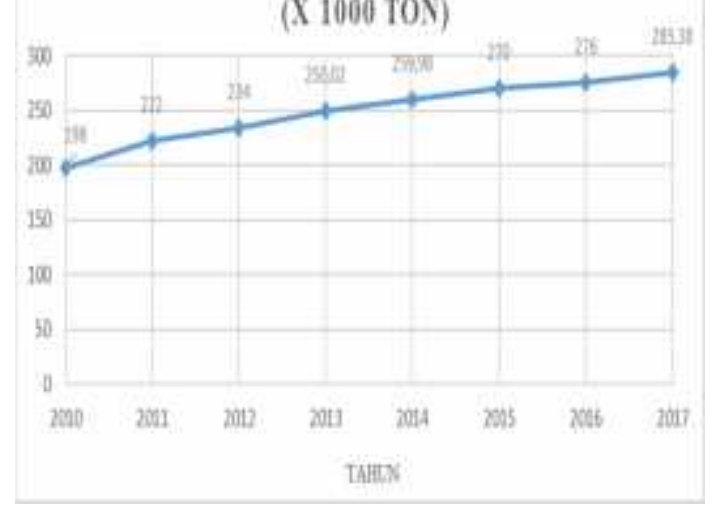

Gambar 1. Tingkat Konsumsi Kopi di Indonesia

Sumber: International Coffee Organization (2018, diolah)

Kebutuhan kopi di Indonesia meningkat setiap tahunnya. Hal ini disebabkan oleh konsumsi kopi masyarakat Indonesia meningkat. Dari Gambar 1 dapat 
dilihat bahwa konsumsi kopi di Indonesia pada tahun 2010 sampai tahun 2017 selalu mengalami peningkatan. Peningkatan tersebut mengindikasikan adanya minat masyarakat terhadap produk kopi. Perubahan gaya hidup dan pola perilaku masyarakat yang konsumtif menjadi salah satu pemicu dari meningkatnya konsumsi kopi di Indonesia (Solikatun, 2015).

Perubahan demografi, lingkungan dan ekonomi membuat daya beli masyarakat semakin tinggi dalam mengonsumsi suatu produk. Sebagian masyarakat tidak lagi mengonsumsii sebuah produk atas dasar kebutuhan, namun hanya sebagai pemuas keinginan untuk menandai kelas, status, atau simbol sosial tertentu sebagai cerminan gaya hidup pada masyarakat modern (Ristinawati 2009).

Peningkatan konsumsi kopi menunjukkan bahwa konsumen kopi dalam negeri merupakan pasar yang potensial sehingga menjadi peluang bisnis bagi para pelaku usaha di Indonesia. Investasi pada industri kopi yang menarik para pelaku usaha dan dinilai sebagai peluang bisnis yang baik adalah usaha kafe dengan konsep kedai kopi. Kedai kopi merupakan salah satu jenis restoran yang dipandang sebagai salah satu tempat yang dapat mewakili gaya hidup sebagian masyarakat.
Selain untuk menikmati kopi, biasanya kedai kopi dimanfaatkan sebagai tempat berkumpul, bersantai, mengerjakan tugas, rapat, berdiskusi, dan lain lain. Suasana yang nyaman, rasa dan variasi menu serta fasilitas pendukung yang banyak ditawarkan merupakan beberapa alasan yang menjadikan kedai kopi sebagai pilihan tempat untuk berkumpul

Menurut Silviatni (2014), Bandung sebagai salah satu simbol wisata kuliner, tidak ketinggalan dalam perkembangan bisnis kedai kopinya. Di daerah Bandung, kedai kopi sangat beragam, dari yang hanya khusus menyediakan kopi hingga kedai kopi yang menyediakan kopi serta makanan pelengkap lainnya. Maraknya kedai kopi tersebut untuk memenuhi kebutuhan masyarakat akan budaya minum kopi Saat ini kedai kopi memberikan fasilitas akses internet, suasana yang nyaman dan bahkan mulai bermunculan kedai kopi dengan desain interior yang unik.

Melihat perubahan gaya hidup masyarakat maka para pelaku bisnis berlomba untuk membuka kedai kopi di daerah Bandung. Pada Tabel 2 dapat dilihat beberapa kedai kopi yang terdapat di daerah Bandung pada tahun 2017.

Kiwari Farmers adalah kelompok tani kopi di Bandung yang memproduksi 
kopi arabika. Meningkatnya jumlah kedai kopi di daerah Bandung menimbulkan persaingan yang semakin ketat dalam industri kopi. Salah satu dampak persaingan tersebut adalah omzet warung kopi Kiwari berfluktuasi selama tahun

Tabel 2. Kedai kopi yang terdapat di daerah Bandung tahun 2017

\begin{tabular}{|c|c|c|c|c|c|}
\hline No. & $\begin{array}{l}\text { Nama kedai } \\
\text { kopi }\end{array}$ & Lokasi & No. & Nama kedai kopi & Lokasi \\
\hline 1 & Mimiti Coffee & $\begin{array}{l}\text { Jl. Sumur } \\
\text { Bandung } 14\end{array}$ & 14 & Boyle's Coffee & $\begin{array}{l}\text { Komp. Surya Setra } \\
\text { Blok C No. } 2\end{array}$ \\
\hline 2 & Call Me Bro & $\begin{array}{l}\text { Jl.Lengkong } \\
\text { Besar 6-8 }\end{array}$ & 15 & $\begin{array}{l}\text { Lula Bakery \& } \\
\text { Coffee }\end{array}$ & Jl. Citarum No.12 \\
\hline 3 & Kiputih Satu & $\begin{array}{l}\text { Jl. Kiputih 1a, } \\
\text { Ciumbuleuit }\end{array}$ & 16 & Woodlane & Jl. Anggrek 36 \\
\hline 4 & Armor Leuir & $\begin{array}{l}\text { Jl. Bukit Pakar } \\
\text { Utara } 10\end{array}$ & 17 & $\begin{array}{l}\text { Pillow Talk Coffee } \\
\& \text { Comfy }\end{array}$ & Jl. Haji Hasan 12 \\
\hline 5 & Daily Breu & Jl. Rontgen 9 & 18 & Yumaju Coffee & $\begin{array}{l}\text { Jl. Maulana Yusuf } \\
10\end{array}$ \\
\hline 6 & $\begin{array}{l}\text { Eiger Coffee } \\
\text { Cihampelas }\end{array}$ & Jl. Cihampelas 22 & 19 & $\begin{array}{l}\text { Abraham and } \\
\text { Smith }\end{array}$ & $\begin{array}{l}\text { Jl. Gudang Selatan } \\
22\end{array}$ \\
\hline 7 & Grind Joe & Jalan Dago 69 & 20 & Barleu Coffeeshop & Jl. Anggrek 55 \\
\hline 8 & Budaraa & $\begin{array}{l}\text { Jl. Bukit Dago } \\
\text { Utara II No.11 }\end{array}$ & 21 & $\begin{array}{l}\text { Ruckerpark Coffee } \\
\text { Culture }\end{array}$ & Jl. Dr. Cipto No.24 \\
\hline 9 & Roempi & Jalan Anggrek 27 & 22 & $\begin{array}{l}\text { Aditi Coffee House } \\
\text { and Space }\end{array}$ & $\begin{array}{l}\text { Jl. K.H. Ahmad } \\
\text { Dahlan No.5 }\end{array}$ \\
\hline 10 & Kopi Barli & $\begin{array}{l}\text { Jl. Prof. Dr. } \\
\text { Sutami No. } 91\end{array}$ & 23 & $\begin{array}{l}\text { Kamar Tujuh } \\
\text { Coffee }\end{array}$ & Jl. Cilamaya No. 1 \\
\hline 11 & Cupola & Jl. Cendana No.3 & 24 & Sejiwa Coffee & J1. Progo 15 \\
\hline 12 & $\begin{array}{l}\text { Ambrogio } \\
\text { Pattiserie }\end{array}$ & J1. Banda 26 & 25 & Contrast Coffee & Jl. Anggrek 46 \\
\hline 13 & $\begin{array}{l}\text { Next } 8 \text { Coffee } \\
\text { and Food }\end{array}$ & Jl. Cendana No.8 & 26 & General.co & $\begin{array}{l}\text { Paskal } \\
\text { Hypersquare }\end{array}$ \\
\hline
\end{tabular}

Sumber : www.pergidulu.com Kedai kopi di Bandung, 2017

2018 (lihat Gambar 2). Dari Gambar 2 dapat dilihat omzet tertinggi terjadi pada bulan Januari, sedangkan yang terendah pada bulan Maret 2018. Hal ini diduga disebabkan oleh jumlah konsumen yang menurun. 


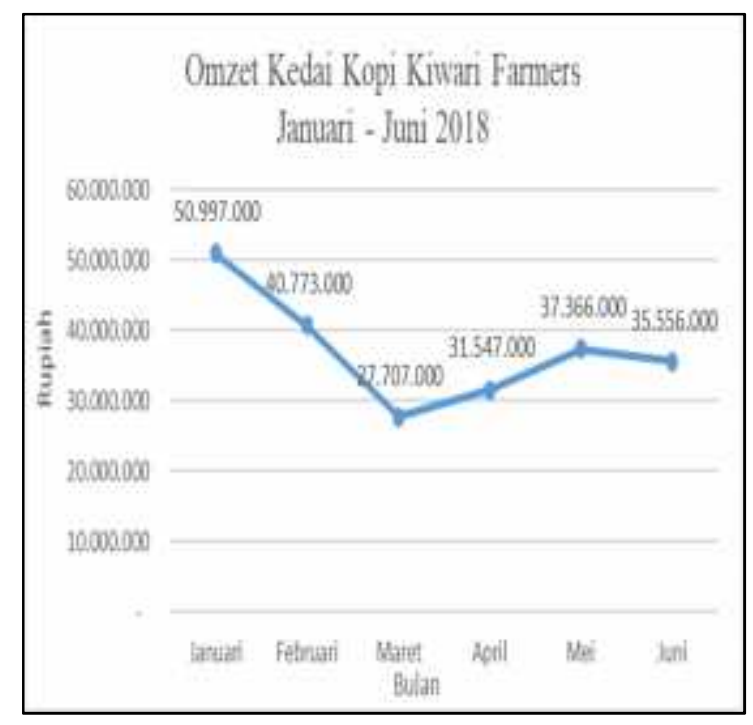

Gambar 2. Omzet Warung Kopi Kiwari Sumber: Kiwari Farmers, 2018

Berdasarkan berbagai uraian di atas, penelitian ini bertujuan mengetahui profil warung Kiwari dan karakteristik konsumennya yang mengonsumsi kopi arabika Manglayang Karlina

\section{METODE PENELITIAN}

Penelitian ini menggunakan desain kualitatif dan kuantitatif dengan teknik penelitian survey terhadap sampel responden berukuran 50 yang datang ke warung kopi Kiwari. Penentuan responden dilakukan secara purposive. Konsumen yang dijadikan responden adalah konsumen yang telah membeli dan mengonsumsi kopi Manglayang Karlina sebanyak 2 kali atau lebih dalam jangka waktu 3 bulan terakhir. Kuesioner diberikan pada hari biasa (weekday) dan akhir pekan (weekend).
Data terdiri dari data primer dan sekunder. Data primer diperoleh dengan menggunakan kuesioner dan wawancara. Data sekunder diperoleh dari hasil penelitian terdahulu, buku yang berkaitan dengan topik penelitian, dokumentasi pada saat melakukan pengumpulan data di warung Kopi Kiwari, serta situs resmi instansi terkait seperti Dinas Pertanian dan Kementrian Pertanian.

Analisis data dan informasi dilakukan secara deskriptif. Untuk mengetahui profil warung kopi Kiwari dilakukan analisis kualitatif berdasarkan pendekatan sistem usaha: Input $\rightarrow$ Proses $\rightarrow$ Output $\rightarrow$ Pemasaran. Sedangkan untuk menggambarkan karakteristik konsumen dilakukan tabulasi distribusi frekuensi, dimana variabel yang diukur adalah: jenis kelamin, usia, tingkat pendidikan, jenis pekerjaan, tingkat pendapatan per bulan, serta domisili reponden.

\section{HASIL DAN PEMBAHASAN Profil warung kopi Kiwari}

Kiwari Farmers merupakan kelompok tani yang bergerak dalam bidang industri kreatif yang berfokus pada komoditas kopi. Nama "Kiwari" berasal dari Bahasa Sunda yang memiliki arti "sekarang" atau "kekinian". Nama tersebut dipilih dengan harapan Kiwari Farmers 
akan mampu menjadi petani yang kekinian, yang mampu mengikuti perkembangan zaman.

Pada skema rantai pasok yang dibuat oleh Kiwari Farmers terdapat market yang merupakan bagian dari hilir dari skema tersebut. Pada tanggal 20 Maret 2016 akhirnya Kiwari Farmers membuka sebuah warung kopi dengan nama Kopi Kiwari yang berada di Jalan Palapa No.55, Padasuka, Cimenyan, Bandung, Jawa Barat. Latar belakang dibentuknya kedai Kopi Kiwari adalah sebagai pusat tempat untuk menjual produk Kiwari Farmers sekaligus merupakan pasar utama dalam rantai pasok Kiwari Farmers. Adapun yang ingin ditunjukan oleh kedai Kopi Kiwari yaitu:

-Memberikan edukasi kepada konsumen mengenai kopi melalui barista di Kopi Kiwari

-Memperkenalkan rasa kopi Jawa Barat dengan strategi pemasaran awal yaitu "Minum kopi sepuasnya, bayar seikhlasnya" atau metode pay as you like. Strategi pemasaran tersebut berlangsung selama 3 bulan dari mulai kedai Kopi Kiwari beroperasi, yaitu pada bulan April sampai Juni 2016.

-Membuat kopi menjadi minuman yang dapat diterima oleh semua lapisan masyarakat
- Produk utama yang dijual di warung Kopi Kiwari adalah kopi yang mereka olah secara mandiri dari hulu hingga hilir yaitu kopi arabika reguler dengan brand Manglayang Karlina dan kopi luwak dengan brand Luwak Manglayang. Kedua produk tersebut sudah siap jual minimal dalam keadaan sudah disangrai (roasted beans). Kedai Kopi Kiwari memberikan pilihan beberapa macam penyajian untuk konsumen saat ingin membeli produk Kiwari Farmers seperti diseduh manual tanpa ampas kopi (kopi filter), diseduh bersama ampas kopi (kopi tubruk), cold brew, espresso, café latte, cappuccino, atau konsumen bisa membeli produk Kiwari Farmers dalam bentuk biji kopi sangrai (roasted beans).

Untuk jenis kopi arabika lain yang dibeli dari petani-petani di Jawa Barat, kedai Kopi Kiwari hanya menyediakan olahan dalam bentuk kopi filter dan kopi tubruk. Selain menjual produk kopi, Kiwari Farmers juga menjual aneka makanan seperti cireng, cilok goreng, cilok rebus, mie goreng, mie rebus, pisang bakar, tahu goreng, dan lain sebagainya serta berbagai macam jenis minuman seperti coklat, lemon tea, teh stevia, teh hijau, teh hitam, dan teh putih yang mereka dapatkan dengan cara membeli dari petani 
lain dan Kiwari Farmers hanya berperan sebagai trader.

Warung Kopi Kiwari memiliki jumlah tenaga kerja sebanyak 5 orang dimana pembagian kerja mereka dibagi dan diatur berdasarkan shifting dan maksimal tenaga kerja yang bertugas per harinya adalah 3 orang. Dalam proses perekrutan tenaga kerja tersebut Kiwari Farmers mencari warga sekitar kedai Kopi Kiwari, hal tersebut bertujuan untuk turut membantu meningkatkan kesejahteraan masyarakat desa sekitar dan untuk mencegah adanya kecemburuan sosial di desa sekitar dengan status tetap untuk semua pekerja. Tidak ada kualifikasi khusus untuk menjadi karyawan warung Kopi Kiwari asalkan mereka mau bekerja dan siap untuk mengikuti aturan yang ada di warung Kopi Kiwari. Akibatnya, pendidikan akhir yang ditempuh tenaga kerja pun bermacam-macam dari mulai SD, SMP, SMA, hingga sarjana.

Tabel 3. Jenis dan harga minuman kopi di warung kopi Kiwari

\begin{tabular}{clcr}
\hline No & \multicolumn{1}{c}{$\begin{array}{c}\text { Jenis } \\
\text { Produk }\end{array}$} & Satuan & $\begin{array}{c}\text { Harga } \\
\text { (Rupiah) }\end{array}$ \\
\hline 1 & $\begin{array}{l}\text { Luwak } \\
\text { Manglayang }\end{array}$ & $\mathrm{Kg}$ & 950.000 \\
2 & $\begin{array}{l}\text { Luwak } \\
\text { Manglayang }\end{array}$ & $\begin{array}{c}\text { Kaleng } \\
(100 \mathrm{~g})\end{array}$ & 100.000 \\
3 & $\begin{array}{l}\text { Luwak } \\
\text { manglayang }\end{array}$ & Gelas & 30.000 \\
4 & Manglayang & Kaleng & 45.000 \\
\hline
\end{tabular}

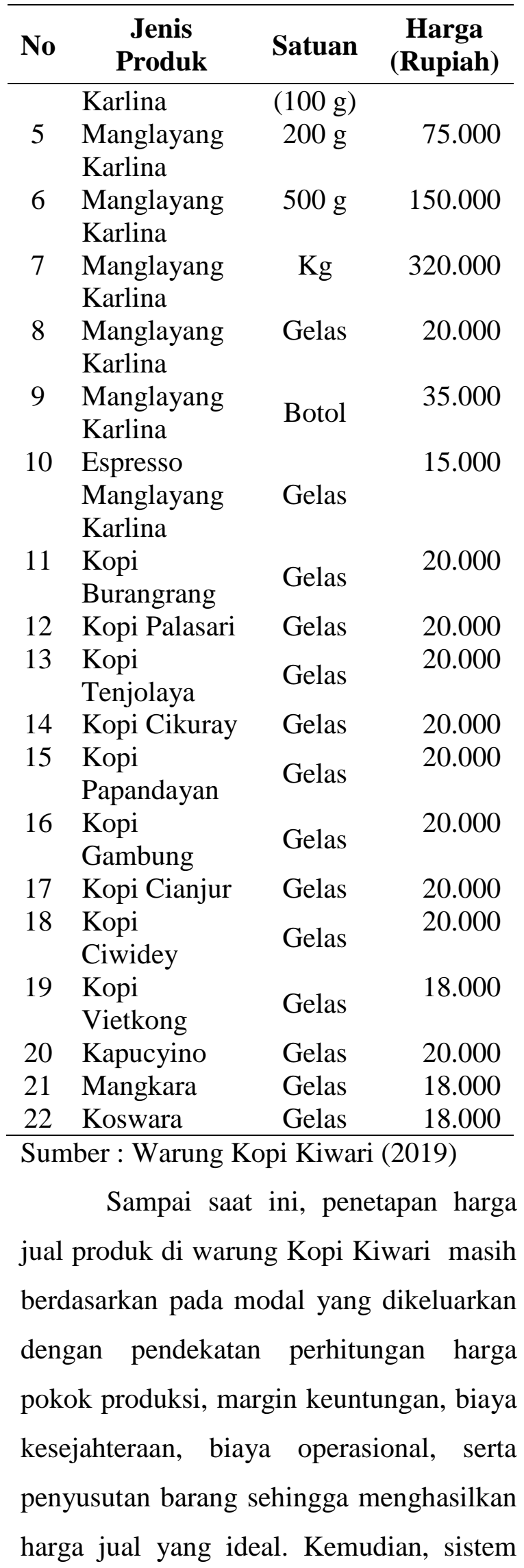




\begin{tabular}{|c|c|c|c|}
\hline \multicolumn{4}{|c|}{$\begin{array}{l}\text { Tabel 4. Jenis dan harga minuman } \\
\text { bukan kopi di warung kopi Kiwari }\end{array}$} \\
\hline No & $\begin{array}{c}\text { Jenis } \\
\text { minuman }\end{array}$ & Satuan & $\begin{array}{c}\text { Harga } \\
\text { (Rupiah) }\end{array}$ \\
\hline 1 & $\begin{array}{l}\text { Green Tea } \\
\text { Latte }\end{array}$ & Gelas & 20.000 \\
\hline 2 & Choco Latte & Gelas & 20.000 \\
\hline 3 & $\begin{array}{l}\text { Lemon } \\
\text { Hungkul }\end{array}$ & Gelas & 16.000 \\
\hline 4 & $\begin{array}{l}\text { Susu } \\
\text { Lemon }\end{array}$ & Gelas & 18.000 \\
\hline 5 & Cascara & Gelas & 15.000 \\
\hline 6 & $\begin{array}{l}\text { Stevia } \\
\text { Jasmine }\end{array}$ & Gelas & 20.000 \\
\hline 7 & $\begin{array}{l}\text { Stevia } \\
\text { Original }\end{array}$ & Gelas & 20.000 \\
\hline 8 & $\begin{array}{l}\text { Stevia } \\
\text { Mangga }\end{array}$ & Gelas & 20.000 \\
\hline 9 & Stevia Rose & Gelas & 20.000 \\
\hline 10 & Stevia Apel & Gelas & 21.000 \\
\hline
\end{tabular}

Harga produk yang dijual disajikan dalam Tabel 3, 4, dan Tabel 5. Pada Tabel 3 tampak bahwa satuan

\section{Tabel 5. Jenis dan harga makanan di} warung kopi Kiwari

\begin{tabular}{rlrr}
\hline No & $\begin{array}{c}\text { Jenis } \\
\text { Produk }\end{array}$ & Satuan & $\begin{array}{c}\text { Harga } \\
\text { (Rupiah) }\end{array}$ \\
\hline 1 & $\begin{array}{l}\text { Cireng } \\
\text { Nyamnyam }\end{array}$ & Porsi & 20.000 \\
2 & $\begin{array}{l}\text { Cilok } \\
\text { Goreng }\end{array}$ & Porsi & 15.000 \\
3 & $\begin{array}{l}\text { Cilok } \\
\text { Seupan }\end{array}$ & Porsi & 15.000 \\
4 & $\begin{array}{l}\text { Goreng } \\
\text { Cau } \\
\text { Panggang } \\
\text { Cau }\end{array}$ & Porsi & 18.000 \\
& Porsi & 20.000 \\
\hline
\end{tabular}

\begin{tabular}{cllr}
\hline No & $\begin{array}{c}\text { Jenis } \\
\text { Produk }\end{array}$ & Satuan & $\begin{array}{c}\text { Harga } \\
\text { (Rupiah) }\end{array}$ \\
\hline 6 & $\begin{array}{l}\text { Cau } \\
\text { Nugget }\end{array}$ & Porsi & 20.000 \\
7 & $\begin{array}{l}\text { Tahu Dulur } \\
\text { Tahu Lada }\end{array}$ & Porsi & 20.000 \\
& $\begin{array}{l}\text { Garam } \\
9\end{array}$ & Porsi & 18.000 \\
10 & $\begin{array}{l}\text { Rie Iyad } \\
\text { Goreng }\end{array}$ & Porsi & 20.000 \\
11 & $\begin{array}{l}\text { Mie Iyad } \\
\text { Kasep }\end{array}$ & Porsi & 16.000 \\
12 & $\begin{array}{l}\text { Cireng } \\
\text { Kuah }\end{array}$ & Porsi & 20.000 \\
13 & $\begin{array}{l}\text { Nasi } \\
\text { Goreng }\end{array}$ & Porsi & 20.000 \\
14 & Kwetiaw & Porsi & 19.000 \\
\hline Sumber: Warung Kopi Kiwari $(2019)$
\end{tabular}

Produk kopi berbeda-beda. Satuan berat kg untuk produk berupa roast beans, satuan kaleng menunjukkan produk tersebut berupa ground beans. Sedangkan satuan botol untuk bentuk cold brew dan satuan gelas menunjukkan berbagai produk minuman kopi.

Kegiatan operasional warung kopi Kiwari dilakukan oleh Direktur operasional, bagian-bagian: Head bar dan manager, barista, waiters, chef dan asisten chef, roaster dan Co Roaster.

\section{Karakteristik responden}

\section{Karakteristik responden berdasarkan jenis kelamin}

Mayoritas responden kopi

Manglayang Karlina adalah laki-laki (lihat Tabel 6). Hal tersebut sesuai dengan temuan Justinus (2015) yang menyatakan 
bahwa kegiatan mengonsumsi kopi biasanya didominasi oleh pria.

Menurut Tabel 6, mayoritas responden adalah laki-laki Namun demikian, responden laki-laki maupun perempuan mempunyai tujuan yang sama

\begin{tabular}{|c|c|c|}
\hline $\begin{array}{c}\text { Jenis } \\
\text { Kelamin }\end{array}$ & Frekuensi & $\begin{array}{c}\text { Persentase } \\
(\%)\end{array}$ \\
\hline Laki-laki & 30 & 60 \\
\hline Perempuan & 20 & 40 \\
\hline Total & 50 & 100 \\
\hline
\end{tabular}

dalam mengonsumsi kopi di warung kopi Kiwari, yaitu sebagai selingan sembari bersantai dan juga bertemu kenalan.

\section{Karakteristik responden berdasarkan usia}

Rata-rata usia responden adalah 20 tahun, dengan rentang 18 - 26 tahun. Karena itu responden dapat dikatakan termasuk golongan usia remaja. Informasi selengkapnya dapat dilihat pada Tabel 7. Dari tabel tersebut dapat diketahui bahwa mayoritas responden berusia 18 - 19 tahun.

Pada usia remaja umumnya seseorang memiliki lebih banyak waktu luang untuk melakukan kegiatan mengonsumsi kopi di kedai kopi. Responden usia remaja juga memiliki kecenderungan untuk mencoba hal-hal baru sehingga mudah terpengaruh ajakan teman atau iklan.

Tabel 7. Sebaran responden berdasarkan usia

\begin{tabular}{ccc}
\hline Kelas & frekuensi & \% \\
\hline $18-19$ & 28 & 56 \\
$20-21$ & 5 & 10 \\
$22-23$ & 15 & 30 \\
$24-25$ & 1 & 2 \\
$26-27$ & 1 & 2 \\
\hline Jumlah & $\mathbf{5 0}$ & $\mathbf{1 0 0}$ \\
\hline
\end{tabular}

Target pasar kopi Manglayang Karlina adalah kalangan usia remaja. Karena itu warung kopi tersebut didesain sedemikian rupa sehingga terkesan modern sehingga disukai oleh kalangan orang muda. Hasil penelitian ini menunjukkan kenyataan sesuai dengan yang ditargetkan.

\section{Karakteristik responden berdasarkan jenjang pendidikan yang sedang ditempuh}

Mayoritas responden kopi Manglayang Karlina (78\%) sedang menempuh pendidikan sarjana seperti tampak pada Tabel 5. Jenjang pendidikan bisa menentukan intelektualitas seseorang dan kelas sosialnya sehingga mempengaruhi keputusan dalam memilih sesuatu yang akan dikonsumsinya.

Pendidikan yang tinggi membuat seseorang lebih berwawasan dan terbuka terhadap hal-hal baru serta perubahan pesat yang terjadi di masyarakat. Akibatnya, 
pemilihan pola konsumsi pun akan terpengaruh; dan maraknya kedai kopi memunculkan kebiasaan mengonsumsi kopi bagi kalangan berpendidikan tinggi.

Mereka menjadikan

Tabel 8. Sebaran responden berdasarkan jenjang pendidikan yang sedang ditempuh

\begin{tabular}{ccc}
\hline $\begin{array}{c}\text { Jenjang } \\
\text { Pendidikan }\end{array}$ & Frekuensi & $(\boldsymbol{\%})$ \\
\hline SD & 0 & 0 \\
SMP & 0 & 0 \\
SMA & 10 & 20 \\
Akademi/Diploma & 1 & 2 \\
Sarjana & 39 & 78 \\
Pasca Sarjana & 0 & 0 \\
\hline Total & $\mathbf{5 0}$ & $\mathbf{1 0 0}$
\end{tabular}

kegiatan mengonsumsi kopi sebagai gaya hidup dan mengisi waktu luang. Konsep edukasi mengenai budidaya dan proses pengolahan kopi yang ditawarkan oleh warung Kopi Kiwari juga menjadi daya tarik bagi responden berpendidikan tinggi. Hal itu dinilai dapat meningkatkan ilmu dan wawasan mereka.

\section{Karakteristik responden berdasarkan status pekerjaan}

Sebelum mengumpulkan data,

variabel status pekerjaan merupakan jenis pekerjaan, seperti pada umumnya dalam mengidentifikasi karakteristik responden. Tetapi setelah data terkumpul, responden terbedakan hanya atas dau kategori yaitu bekerja dan belum/tidak bekerja.

Pada Tabel 9 dapat dilihat bahwa responden yang paling sering membeli kopi Manglayang Karlina adalah mereka yang belum/tidak bekerja (88\%). Hal ini

Tabel 9. Sebaran responden berdasarkan status pekerjaan

\begin{tabular}{|c|c|c|}
\hline $\begin{array}{l}\text { Status } \\
\text { Pekerjaan }\end{array}$ & Frekuensi & $\%$ \\
\hline Bekerja & 6 & 12 \\
\hline $\begin{array}{l}\text { Belum/Tidak } \\
\text { Bekerja }\end{array}$ & 44 & 88 \\
\hline Total & 50 & 100 \\
\hline
\end{tabular}

membuktikan bahwa responden mampu membeli kopi Manglayang Karlina walaupun mereka belum/tidak bekerja. Artinya, harga jual kopi masih dapat dijangkau oleh responden tersebut dari uang sakunya. Jika dikaitkan dengan informasi dari Tabel 7, dimana sebagian besar responden adalah mereka yang berusia 18 - 19 tahun, yang artinya masih berstatus pelajar atau mahasiswa, maka hal ini konsisten.

Hampir semua responden yang belum/tidak bekerja (42 dari 44 responden) merupakan pelajar atau mahasiswa. Mereka menjadikan kegiatan mengonsumsi kopi sebagai sarana untuk berdiskusi, menyelesaikan tugas ataupun hanya sekedar bersantai. Perasaan nyaman yang muncul saat mengonsumsi kopi menjadi salah satu alasan mereka membeli kopi. Hal itu sangat membantu mereka dalam mengerjakan tugas 
Karakteristik responden berdasarkan
pendapatan atau uang saku per bulan

Salah satu faktor yang mempengaruhi seseorang dalam membeli suatu barang adalah daya belinya. Daya beli dapat dilihat dari tingkat pendapatan /uang saku per bulan. Semakin tinggi pendapatan seseorang, semakin tinggi pula daya belinya.

Responden dikelompokkan menjadi tiga kelas pendapatan sesuai klasifikasi World Bank (Kusno, 2018). Klasifikasi tersebut adalah: 1) kelas menengah bawah (< Rp 2.600.000), 2) kelas menengah (Rp 2.600.000 - Rp 6.000.000), dan 3) kelas menengah atas (> Rp 6.000.000).

Berdasarkan Tabel 10, rata-rata pendapatan atau uang saku per bulan responden kopi Manglayang Karlina adalah Rp 1.528.000. Jadi termasuk dalam kelas menengah bawah. Rentang pendapatan/uang saku adalah $\mathrm{Rp} 700.000$ Rp 4.100.000 per bulan. Mayoritas responden $\quad(92 \%) \quad$ memiliki pendapatan/uang saku per bulan di bawah Rp 2.600.000.

Tabel 10. Seabaran responden berdasarkan pendapatan/uang saku per bulan

\begin{tabular}{ccc}
\hline $\begin{array}{c}\text { Pendapatan/uang } \\
\text { saku per bulan (Rp) }\end{array}$ & Frekuensi & $(\boldsymbol{\%})$ \\
\hline$<2.600 .000$ & 46 & 92 \\
$2.000 .000-6.000 .000$ & 4 & 8 \\
\hline
\end{tabular}

\begin{tabular}{ccc}
\hline $\begin{array}{c}\text { 6.000.000 } \\
\text { Total }\end{array}$ & 0 & 0 \\
& $\mathbf{5 0}$ & $\mathbf{1 0 0}$ \\
\hline Jika dikaitkan dengan & status
\end{tabular}

pekerjaan responden dimana mayoritasnya tidak atau belum bekerja, serta bersatus pelajar atau mahasiswa, maka sebaran pendapatan/uang saku ini konsisten. Hanya 4\% responden yang termasuk golongan menengah. Mereka adalah responden yang sudah bekerja dimana pekerjaannya adalah wirausaha.

\section{Karakteristik responden berdasarkan domisili}

Banyaknya responden yang berasal dari dalam Bandung sedikit lebih banyak dibandingkan dengan yang dari luar Bandung; tepatnya $27 \%$ banding $23 \%$ (lihat Tabel 8). Hal itu bisa berarti bahwa kopi Manglayang Karlina memiliki daya tarik terhadap konsumen dari berbagai daerah luar Bandung. Domisili responden luar Bandung antara lain adalah Sumedang, Cimahi, Jakarta, dan Banten. Kenyataan ini sesuai dengan harapan warung Kopi Kiwari yaitu terus mengembangkan dan meningkatkan penjualan ke berbagai daerah. 
Tabel 11. Sebaran responden berdasarkan domisili

\begin{tabular}{ccc}
\hline Domisili & Frekuensi & \% \\
\hline $\begin{array}{c}\text { Luar } \\
\text { Bandung } \\
\text { Dalam } \\
\text { Bandung }\end{array}$ & 23 & 46 \\
\hline Total & 27 & 54 \\
\hline
\end{tabular}

Konsumen yang berdomisili di dalam Bandung yang lebih sering mengonsumsi kopi Manglayang Karlina disebabkan karena lokasi jual produk yang berdekatan dengan tempat tinggal mereka. Hal ini sesuai dengan hasil penelitian Vioni (2013), yang menyatakan bahwa konsumen yang berkunjung sebagian besar berasal dari kota dimana restoran tersebut berada. Kopi Manglayang Karlina berada di kedai Kopi Kiwari yang berlokasi di Bandung, tentunya akan lebih mudah dijangkau oleh konsumen yang berdomisili di daerah Bandung.

\section{KESIMPULAN DAN SARAN}

Warung kopi Kiwari merupakan tempat utama untuk menjual produk yang dihasilkan oleh kelompok tani Kiwari Farmers. Bahan baku kopi diperoleh dari kebun milik sendiri, kemudian diolah secara mandiri dari hulu hingga hilir. Produk yang dihasilkan adalah kopi arabika reguler dengan nama Manglayang Karlina dan kopi luwak dengan nama Luwak Manglayang. Kedua produk tersebut sudah siap jual minimal dalam keadaan sudah disangrai (roasted beans). Selain di warung Kiwari, pemasaran dilakukan juga melalui media sosial dan market place.

$$
\text { Mayoritas responden kopi }
$$

Manglayang Karlina adalah laki-laki remaja yang belum bekerja dengan ratarata uang saku Rp 1.568.000 per bulan. Pada umumnya mereka sedang menempuh pendidikan sarjana, dan berdomisili di dalam Bandung.

\section{DAFTAR PUSTAKA}

Arikunto, S. 2010. Prosedur Penelitian Suatu Pendekatan Praktik. Jakarta: Rineka Cipta.

Asosiasi Eksportir Kopi Indonesia. Jakarta. www.aeki-aice.org. Diakses pada Agustus 2018

Ayelign, A., K. Sabally. 2013. "Determination of Chlorogenic Acids (CGA) in Coffee Beans Using HPLC". American Journal of Research Communication. Vol 1 (2), halaman 78-91.

Badan Pusat Statistik Indonesia. www.bps.go.id. Diakses pada Juli 2018.

BPS Provinsi Jawa Barat, 2016. Jawa Barat Dalam Angka 2016. Badan Pusat Statistik Provinsi Jawa Barat.

Creswell JW. 2010. Research Design. Pendekatan Kualitatif, Kuantitatif dan Mixed. Edisi Ketiga (Terjemahan). Pustaka Pelajar: Yogyakarta

Damanik, Anita Magdalena. 2008. Analisis Sikap dan Preferensi Konsumen terhadap Coffee Shop De Koffie Pot Bogor. Jurusan Ilmu-ilmu Sosial 
Ekonomi Pertanian. Fakultas Pertanian. Bogor: Institut Pertanian Bogor.

Direktorat Jenderal Perkebunan. 2014. Statistik Perkebunan Indonesia: Kopi 2013-2015. Kementerian Pertanian. Jakarta.

ED. 2014. Mengenal Jenis-jenis Kopi. Riau: Sekertariat Badan Koordinasi Penyuluhan Provinsi Riau.

Engel, James F, et.al, 1994, Consumer Behavior, Jilid 1, Alih Bahasa Budiyanto, Jakarta: Binarupa Aksara.

Food and Agriculture Organization of United Nation (FAO). 2015. www.faostat.fao.org. Diakses pada Agustus 2018.

Hastuti. 2003. Stereotipe dan Komoditisasi Perempuan dalam Iklan. Jurnal Perempuan. Jakarta : YJP.

International Coffee Organization (ICO). 2018. www.ico.org. Diakses pada Juli 2018

Kotler P. 2005. Manajemen Pemasaran. Edisi Ke-11. Molan B, Penerjemah. Jakarta (ID): PT.Indeks. Terjemahan dari: Marketing Management. 11th Edition.
Kotler, Armstrong. (2008). Prinsip-Prinsip Pemasaran 1, Edisi Kedua Belas. Jakarta: Erlangga.

Kotler, Philip \& Kevin L., Keller. (2009). Manajemen Pemasaran. Terjemahan: Bob Sabran. Edisi 13 Jilid 1 dan 2. Indonesia: Penerbit Erlangga

Kotler, Philip. 2007. Manajemen Pemasaran. Jakarta: PT. Indeks

Kusno, Kuswarini. A. Imannurdin, Nursyamsiyah, dan E. Djuwendah 2018. Analysis of Rice Purchase Decision on Rice Consumer in Bandung City. IOP Conf. Series: Earth and Environmental Science.

Nawrot, P., S. Jordan., J. Eastwood., J. Rotstein., A. Hugenholtz., M. Feeley. 2003. Effects of Caffeine on Human Health. Food Additives and Contaminants. Vol. 20, No. 1, halaman 1-30.

Panggabean, Eddy. 2011. Buku Pintar Kopi. Jakarta: AgroMedia Pustaka

Rahardjo, Pudji. 2012. Panduan Budidaya dan Pengolahan Kopi Arabika dan Robusta. Penebar Swadaya: Jakarta.

Rahardjo, Pudji. 2012. Panduan Budidaya dan Pengolahan Kopi Arabika dan Robusta. Penebar Swadaya: Jakarta. 